\title{
Wavelength dependence of machining performance in UV-, VIS- and NIR-laser cutting of wood
}

\author{
Satoshi Fukuta ${ }^{1} \cdot$ Masaki Nomura $^{1} \cdot$ Takeshi Ikeda $^{2} \cdot$ Masaki Yoshizawa $^{2} \cdot$ \\ Mariko Yamasaki ${ }^{3} \cdot$ Yasutoshi Sasaki $^{3}$
}

Received: 4 December 2015/ Accepted: 18 March 2016/Published online: 7 April 2016

(C) The Japan Wood Research Society 2016

\begin{abstract}
Cutting of wood using short-wavelength (266-, 355-, 532-, and 1064-nm) lasers was carried out and wavelength dependence in relation to machining performance and post-processing appearance was investigated. We found that a 355-nm-wavelength laser achieves the greatest machining performance. The variation in machining performance between different wavelengths was due to the different light absorptances of the woods: when we measured the spectral reflectance of the woods, we found that the greater the machining performance for a wavelength, the lower its reflection of light (and thus the greater its absorption). Assuming that the absorption of ultraviolet wavelength of $355 \mathrm{~nm}$ by wood is due to lignin, a lignin-free cellulose board was prepared for further investigation, and the same machining and measurements were conducted. The results showed that machining progresses well via the absorption of laser light by lignin at the ultraviolet wavelength of $355 \mathrm{~nm}$. On the other hand, when this cellulose board was impregnated with phenolic resin, there was high absorption of light between the ultraviolet range and wavelengths near $600 \mathrm{~nm}$, machining progressed well at wavelengths of 355 and $532 \mathrm{~nm}$.
\end{abstract}

Parts of this report were presented at the 9th Meeting of the Tokai Branch, Society of Materials Science, Japan, Nagoya, March 2015.

Satoshi Fukuta

satoshi_2_fukuta@pref.aichi.lg.jp; fukuta@aichi-inst.jp

1 Industrial Research Center, Aichi Center for Industry and Science Technology, 1-157-1 Onda-cho, Kariya, Aichi 448-0013, Japan

2 Laserx Co., Ltd, 7 Kofukada, Shinbayashi-cho, Chiryu, Aichi 472-0017, Japan

3 Graduate School of Bioagricultural Science, Nagoya University, Furo-cho, Chikusa-ku, Nagoya, Aichi 464-8601, Japan
Keywords Laser cutting - Short-wavelength laser . Wavelength dependence

\section{Introduction}

As organic materials exhibit good absorption of $\mathrm{CO}_{2}$ laser light, $\mathrm{CO}_{2}$ laser of wavelength $10.6 \mu \mathrm{m}$ has been applied almost exclusively in the machining of wood $[1,2]$. As the laser can provide high output power at a relatively low cost, $\mathrm{CO}_{2}$ laser has been used for cutting and welding applications that require high-speed machining with high output power, not only of wood but also other materials. Meanwhile, in the field of precision machining, shortwavelength lasers are being used that have, for example, wavelengths in the vicinity of Nd:YAG lasers (wavelength $1064 \mathrm{~nm}$ ) and other, even shorter wavelengths. This is because, as the theoretical focal point diameter is proportional to wavelength, the use of short-wavelength lasers enables precise machining. In addition, lasers are normally irradiated at a short pulse width, as shortening the pulse width allows heat effects to the surrounding area to be controlled while increasing the peak power. In recent times, shorter and shorter pulse widths are being achieved, reaching nano-, pico-, and even femtoseconds.

Meanwhile, in our previous research [3], we attempted wood machining using a type of short-wavelength laser, ultraviolet (UV) lasers, specifically, third-harmonic-generation Nd:YLF laser and $\mathrm{Nd}: \mathrm{YVO}_{4}$ laser (wavelengths 349 and $355 \mathrm{~nm}$, respectively), and collected basic performance data. In practical terms, when we performed cutting, hole-drilling and then incising at the drilling site, we observed the superiority and effectiveness of these lasers: we were able to conduct precise cutting with little heat effect, as well as hole-drilling with an extremely high 
aspect ratio, in a relatively short machining time. While one could use various other wavelengths that are generally classified as "short-wavelength", other than the wavelengths of 349 and $355 \mathrm{~nm}$ used in our previous study, we have not found any reports of testing for a suitable wavelength in relation to wood machining. While there is one case [4] of hole-drilling at a depth of several millimeters by exposing wood to a pulse-irradiation ruby laser with a wavelength of $694 \mathrm{~nm}$, this case was from an emerging era when laser had only just been discovered, and it is likely that the types of lasers that could be irradiated were limited. Hattori et al. [5] compared the critical machining energy of Nd:YAG laser and $\mathrm{CO}_{2}$ laser, but their findings were only on Nd:YAG laser, and no detailed quantitative evaluation has since been conducted.

Thus, in this study, we tested for suitable wavelength for wood machining by comparing the wood-machining performance of the base wavelength of $\mathrm{Nd}: \mathrm{YVO}_{4}$ laser, $1064 \mathrm{~nm}$, and of its second-harmonic generation (wavelength $532 \mathrm{~nm}$ ), its third-harmonic generation (wavelength $355 \mathrm{~nm}$ ), and its fourth-harmonic generation (wavelength $266 \mathrm{~nm}$ ), obtained by wavelength conversion, under uniform conditions. We also investigated the causes behind the results.

\section{Materials and methods}

\section{Wood specimens}

The specimens used were heartwood of Japanese cedar (Cryptomeria japonica, hereafter, cedar), heartwood of Japanese larch (Larix kaempferi, hereafter, larch), and beech (Fagus crenata). From these woods, straight grain test specimens of $12 \mathrm{~mm} \quad(\mathrm{~L}) \times 6 \mathrm{~mm} \quad(\mathrm{~T}) \times 70 \mathrm{~mm}$ (R) were prepared [with the exception of the beech, which was $4 \mathrm{~mm}(\mathrm{~T})]$. The partial density variation of cedar and larch is large because of the effect of annual rings. All machining was conducted on early wood: density was measured for each segment of early wood cut out, with the air-dried density of the cedar and larch being 0.31 and $0.35 \mathrm{~g} / \mathrm{cm}^{3}$, respectively. The machining area was not limited for the beech, and the air-dried density of the beech was $0.62 \mathrm{~g} / \mathrm{cm}^{3}$. All specimens were collected with end matching in the grain direction, and all were air-dried specimens having around $10 \%$ moisture content.

\section{Cellulose board specimens}

In addition to the above woods, as a lignin-free material, a cellulose board specimen was prepared with $0.77 \mathrm{~g} / \mathrm{cm}^{3}$ density using the following procedure. Briefly, a 6-mmthick board was prepared by layering a predetermined number of sheets of cellulose non-woven fabric (BEMCOT M-3II; Asahi Kasei Fibers Co.), while spraying with water, such that its water content was homogenous, compressing the specimen to $6 \mathrm{~mm}$ with a $120^{\circ} \mathrm{C}$ hot press, and then drying it in this state. This non-woven fabric uses cotton linter (the fuzz hairs attached to cotton seeds) as its raw material, and is a long-fiber non-woven fabric considered to be composed of almost $100 \%$ cellulose.

Furthermore, we prepared a phenolic resin-impregnated cellulose board (hereafter, impregnated board) by impregnation treatment with water-soluble, low-molecular phenolic resin. Its density was $0.79 \mathrm{~g} / \mathrm{cm}^{3}$ and its weight ratio of impregnated resin was $40 \%$. This board was formed by diluting a water-soluble, low-molecular phenolic resin (BRL-120Z; Showa Denko Co.) to a resin density of $33.7 \%$, impregnating to the non-woven fabric with it, layering and then drying it, and finally thermosetting the resin in a $140{ }^{\circ} \mathrm{C}$ hot press.

\section{Laser irradiation and machining conditions}

The laser irradiation and machining conditions are given in Table 1 . The power defined in Table 1 is actual measurement gauged with a power sensor at the output end. The laser used was a LD excitation Q-switched solid-state laser HIPPO 1064-17 by Spectra-Physics, and four wavelengths were set: the base wavelength of a $\mathrm{Nd}: \mathrm{YVO}_{4}$ laser, $1064 \mathrm{~nm}$, and its second-harmonic generation (wavelength $532 \mathrm{~nm}$ ), third-harmonic generation (wavelength $355 \mathrm{~nm}$ ), and fourth-harmonic generation (wavelength $266 \mathrm{~nm}$ ), obtained through wavelength conversion. As shown in Fig. 1, cutting was conducted at the early wood on straight grain surface (or at an arbitrary site in the case of beech) in the grain direction, and the travel speed of the specimens was varied as per the conditions set out in Table 1. The focal point of the laser was set at the specimen surface for which the most efficient result was obtained in our previous study [3], and assist gas blower was not used.

After machining, kerf width was measured using a microscope. A larch specimen after machining is shown in Fig. 2. Figure 2a shows the kerf observed on the specimen surface. Each specimen was then split along the kerf, and kerf depth was obtained from the machining mark. Figure $2 \mathrm{~b}$ shows the split cross-section. The machining mark could be distinguished by discoloration of the cross-section. For specimens that had shallow kerf and thus could not be split, and specimens for which the machining mark was difficult to discern, kerf depth was obtained by observing the specimen edge with a microscope. Figure $2 \mathrm{c}$ shows the kerf observed on the specimen edge with a microscope. Based on this kerf depth, wood machining performance was determined for each wavelength. These were compared for lasers with an output power of $2.0 \mathrm{~W}$ 
Table 1 Laser irradiation and machining conditions

\begin{tabular}{|c|c|c|c|c|c|c|c|}
\hline Wavelength (nm) & 266 & 355 & & & 532 & 1064 & \\
\hline Pulse width (ns) & 11 & 12 & & & 13 & 15 & \\
\hline Pulse frequency $(\mathrm{kHz})$ & 50 & & & & & & \\
\hline Focal length (mm) & $\mathrm{f} 40$ & & & & & & \\
\hline Theoretical focal point diameter $(\mu \mathrm{m})$ & 5.9 & 11.0 & & & 12.3 & 11.7 & \\
\hline Power (W) & 2.0 & 1.0 & 2.0 & 5.0 & 5.0 & 5.0 & 12.0 \\
\hline \multirow[t]{4}{*}{ Travel speed $(\mathrm{mm} / \mathrm{s})$} & 10 & 10 & 10 & 25 & 25 & 25 & 25 \\
\hline & 25 & 25 & 25 & 50 & 50 & 50 & 50 \\
\hline & 50 & 50 & 50 & 125 & 125 & 125 & 125 \\
\hline & 125 & 125 & 125 & 250 & 250 & 250 & 250 \\
\hline
\end{tabular}

Laser beam (Q-switched pulse laser irradiation)

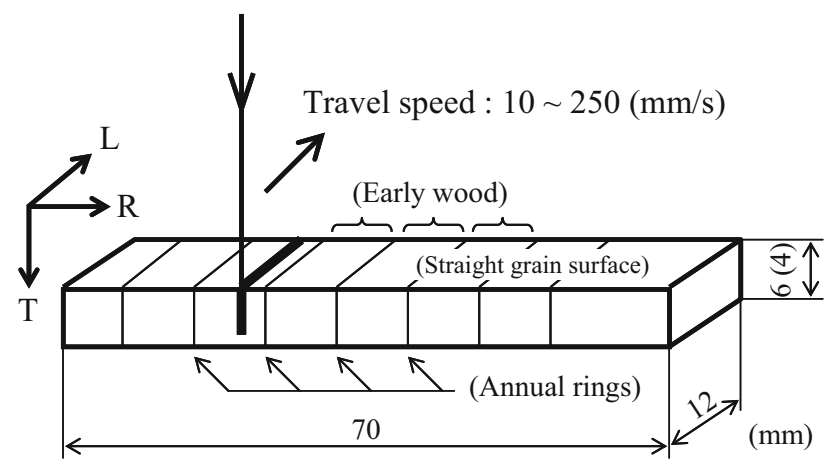

Fig. 1 Machining method

and wavelengths of 266 and $355 \mathrm{~nm}$, and with an output power of $5.0 \mathrm{~W}$ and wavelengths of 355, 532, and $1064 \mathrm{~nm}$. Other output power conditions were employed for finding the machining threshold that would serve as the minimum output power at which machining was possible.

\section{Spectral reflectance measurements}

For each of the five types of specimens, an ultravioletvisible-near-infrared spectrometer (Hitachi High-Technologies Co. U-4000) was used to obtain the total reflectance of light between wavelengths 240 and $1500 \mathrm{~nm}$. For wood specimens, flat grain test specimens of $20 \mathrm{~mm}$ $(\mathrm{L}) \times 20 \mathrm{~mm}(\mathrm{~T}) \times 3 \mathrm{~mm}(\mathrm{R})$ were obtained from the same wood pieces used for cutting tests, and its early wood part was measured. The board specimens of $20 \times 20 \mathrm{~mm}$ were cut randomly from the board prepared by abovementioned method.

\section{Results and discussion}

\section{Wavelength dependence of machining performance}

Figure 3 shows the relationship between travel speed and kerf depth of the three wood specimens. Figure 3 a shows the results of a comparison between the wavelengths $355 \mathrm{~nm}, 532 \mathrm{~nm}$, and $1064 \mathrm{~nm}$ for each specimen. At $1064 \mathrm{~nm}$, machining was not possible at an output power of $5.0 \mathrm{~W}$, and, therefore, the output power was set to $12.0 \mathrm{~W}$, but even then, machining was not possible for larch and beech at travel speeds of 125 or $250 \mathrm{~mm} / \mathrm{s}$. At $532 \mathrm{~nm}$, machining was not possible for larch at $250 \mathrm{~mm} / \mathrm{s}$ or for beech at 125 or $250 \mathrm{~mm} / \mathrm{s}$. As our previous report [3] stated, the higher the density of the specimen, the greater the energy required for machining; accordingly, kerf depth became slightly shallower from cedar to larch to beech,
Fig. 2 A larch specimen after machining. Wavelength: 355 nm, Power: $2.0 \mathrm{~W}$, Travel speed: $25 \mathrm{~mm} / \mathrm{s}$. a Kerf observed on the specimen surface. b Split crosssection. c Kerf observed on the specimen edge

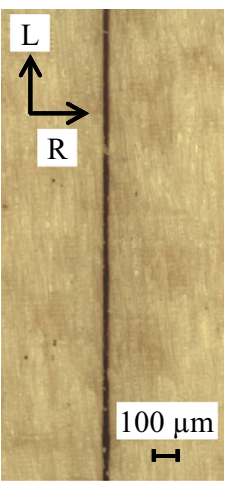

(a)

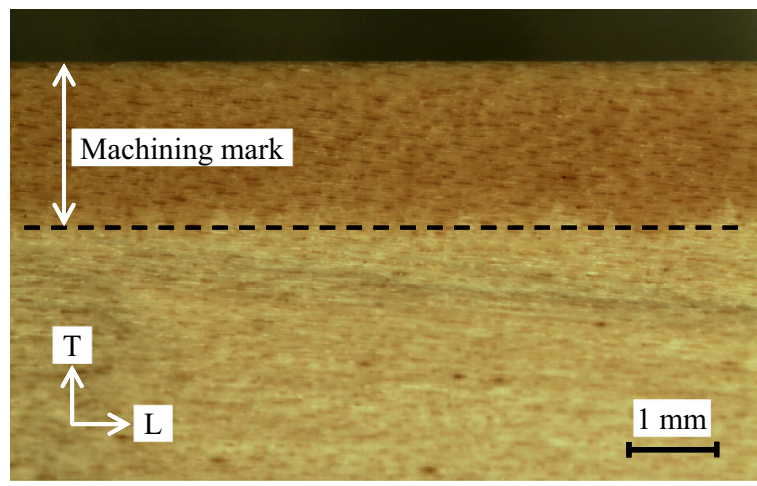

(b)

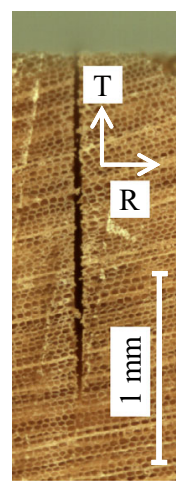

(c) 

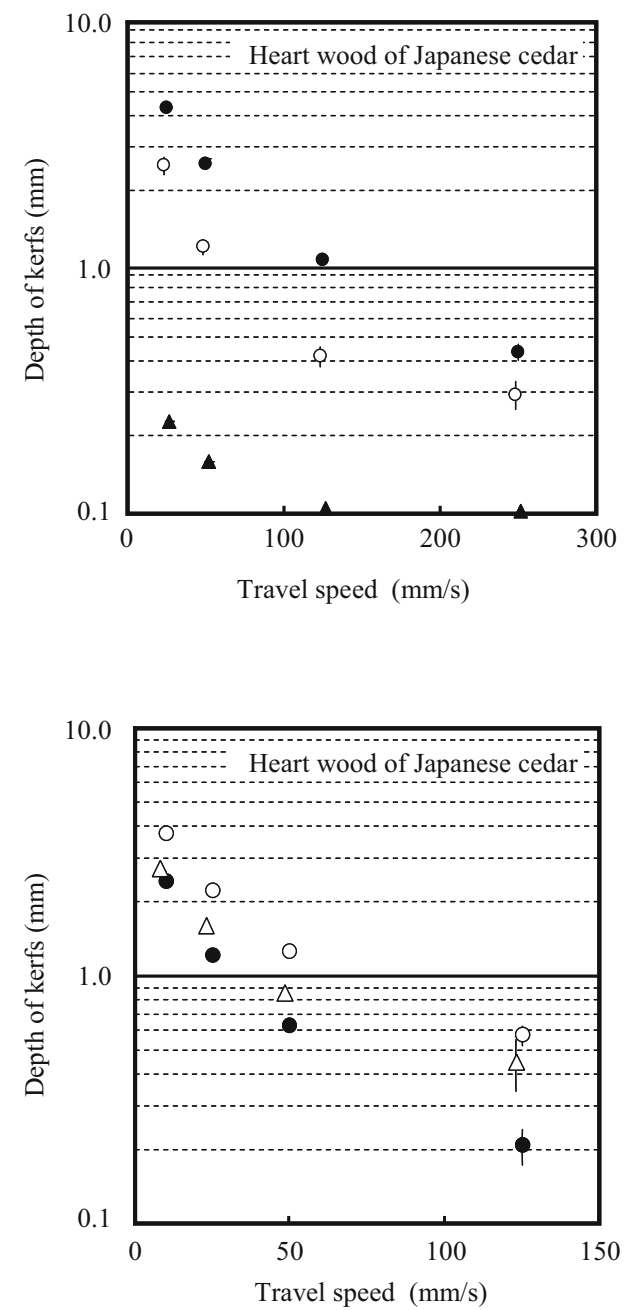

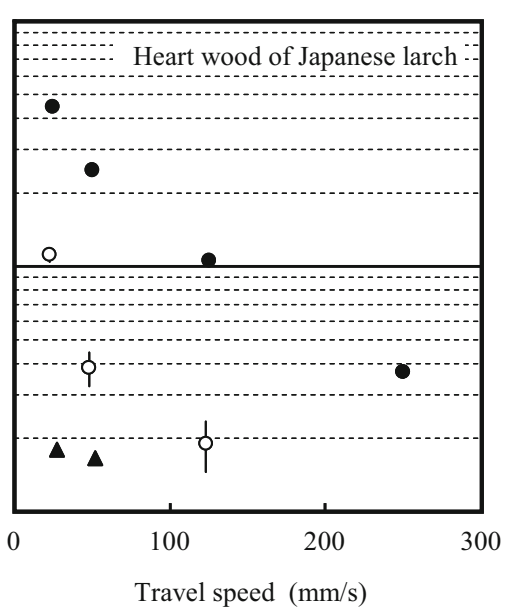

(a)

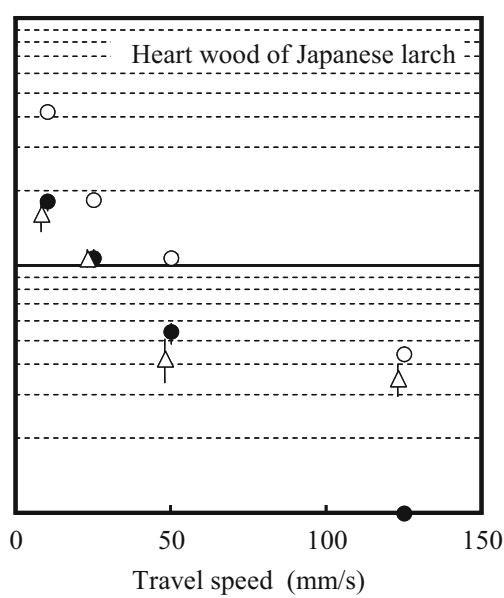

(b)
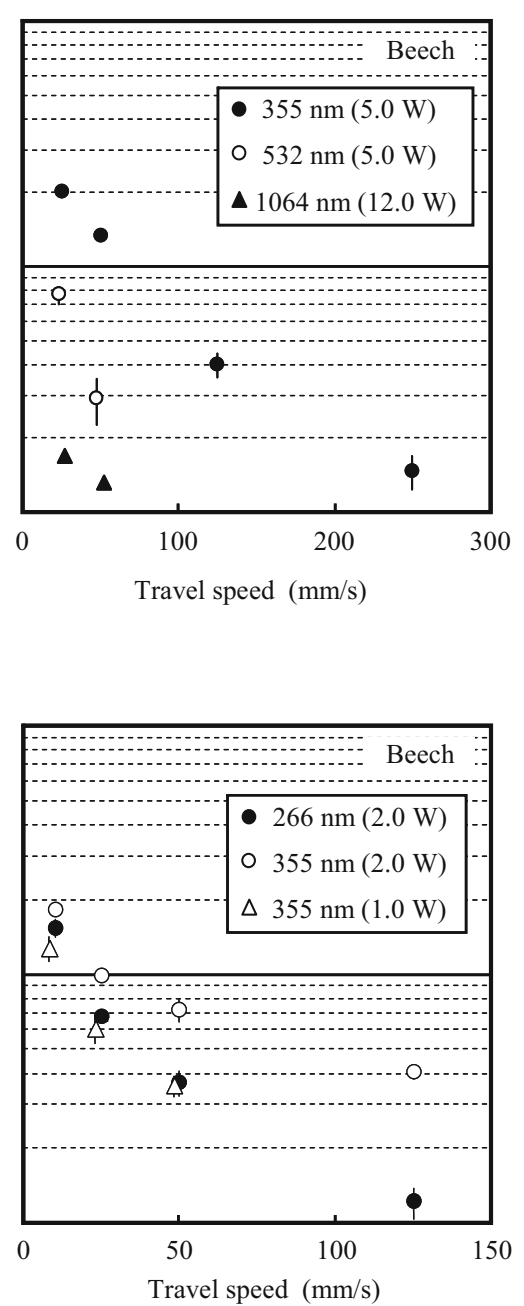

Fig. 3 Relationship between travel speed and kerf depth. a Comparison between 355, 532, and 1064 nm. b Comparison between 266 and $355 \mathrm{~nm}$

clearly showing the machining limits. When we compare the three wavelengths, $355 \mathrm{~nm}$ clearly yielded superior machining performance. Figure $3 \mathrm{~b}$ gives the results of a similar comparison between 266 and $355 \mathrm{~nm}$. At the same output power, $355 \mathrm{~nm}$ produced deeper kerfs than $266 \mathrm{~nm}$, and its machining performance was superior. The experiment was repeated under an additional set of conditions, with an output power of $1.0 \mathrm{~W}$ and a wavelength of $355 \mathrm{~nm}$, but this yielded approximately the same results as $266 \mathrm{~nm}$ at an output power of $2.0 \mathrm{~W}$ for all the specimens. In other words, of the four wavelengths used, $355 \mathrm{~nm}$ yielded the greatest machining performance.

Next, Fig. 4 shows the relationship between travel speed and kerf width of the wood specimens. Figure 4a gives the results of a comparison of wavelengths 355,532 , and $1064 \mathrm{~nm}$ for each of the specimens. At $355 \mathrm{~nm}$, the kerf width for each of the specimens was $20-30 \mu \mathrm{m}$, the same as the diameter of the drilled holes in our previous report [3]. In contrast, although the theoretical focal point diameter differed little from that of a wavelength of $355 \mathrm{~nm}$, at a wavelength of $1064 \mathrm{~nm}$, the kerf width was extremely large, and showed a growing trend with slower travel speed. Even at a wavelength of $532 \mathrm{~nm}$, larch and beech showed a widening trend at slow speeds. At wavelengths of 1064 and $532 \mathrm{~nm}$, the post-processing appearance, particularly under the slow-speed conditions that produced wider kerfs, differed greatly from that at $355 \mathrm{~nm}$. While at these wavelengths, the heat effects, i.e. carbonization around the kerf and on the cut plane were significant enough to be recognizable by visual observation, at $355 \mathrm{~nm}$ only a slight change of color was observed, only on the cut plane. Figure $4 \mathrm{~b}$ gives the results of a similar comparison, between 266 and $355 \mathrm{~nm}$. At $355 \mathrm{~nm}$, the width was slightly narrower than for the $5.0-\mathrm{W}$ output power cases shown in 

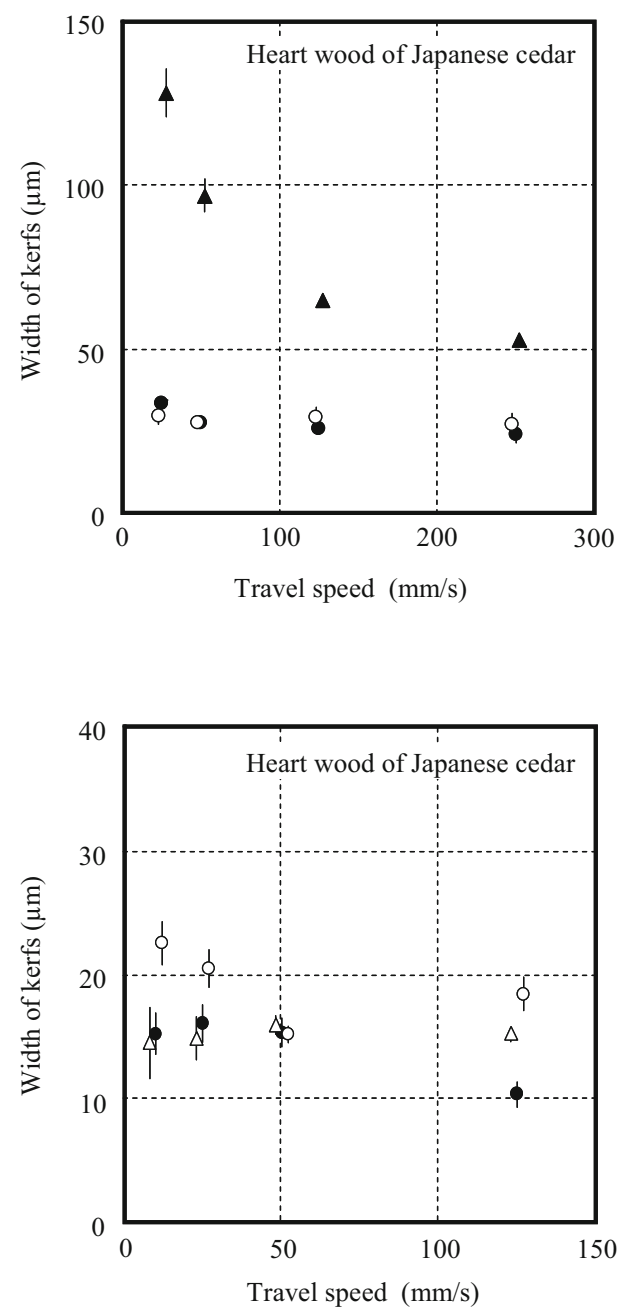

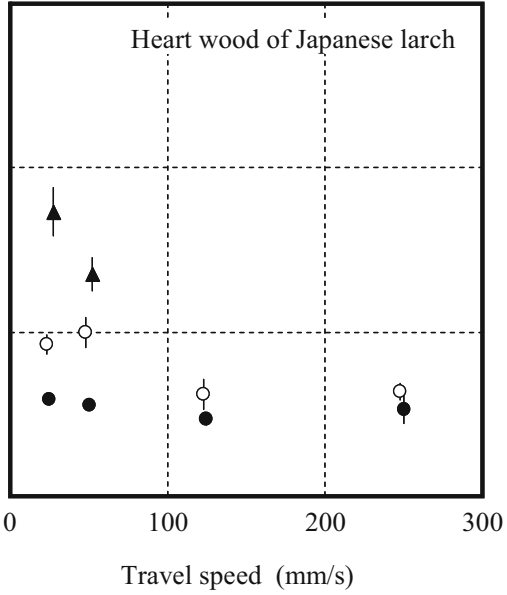

(a)

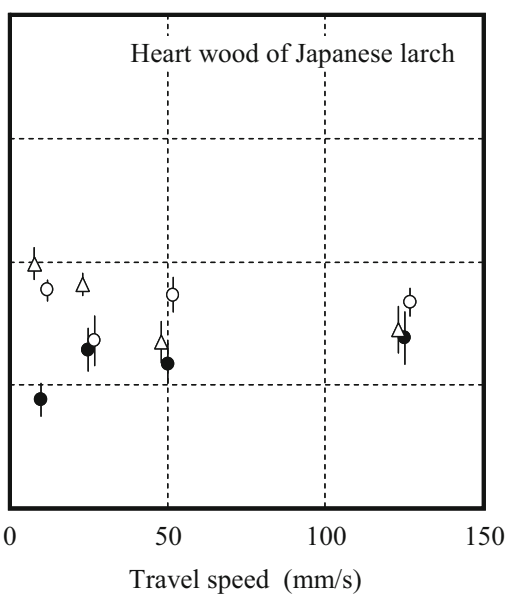

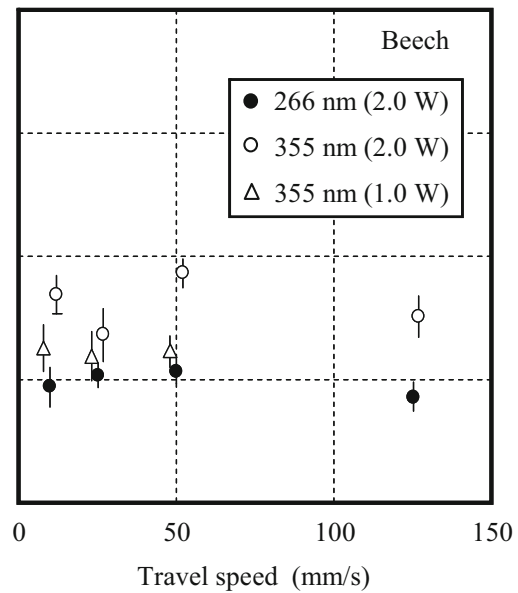

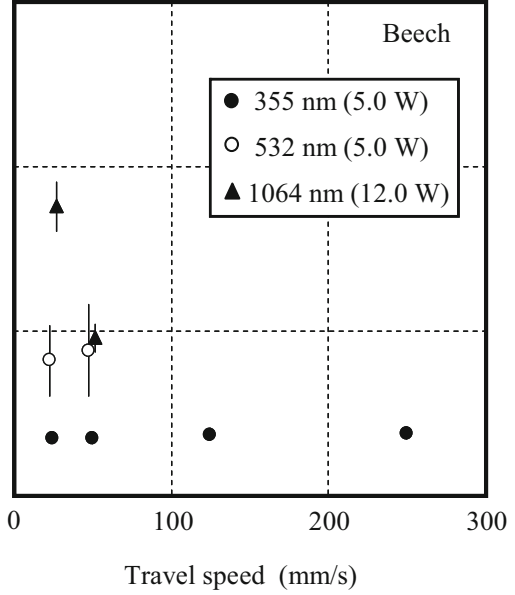

Travel speed $(\mathrm{mm} / \mathrm{s})$

(b)

Fig. 4 Relationship between travel speed and kerf width. a Comparison between 355, 532, and $1064 \mathrm{~nm}$. b Comparison between 266 and $355 \mathrm{~nm}$

Fig. 4a. The theoretical focal point diameter at $266 \mathrm{~nm}$ was smaller than that at $355 \mathrm{~nm}$, and so the kerf width at a wavelength of $266 \mathrm{~nm}$ was slightly narrower overall. The post-processing appearance exhibited very slight heat effects for both.

Laser machining is essentially heat processing. When exposed to extremely high-energy-density ultra-shortpulse laser, a material is instantly evaporated and eliminated. Because this occurs in an extremely short period, the heat effects to the surrounding area (heat transmission) are minimal, and ablation phenomena are dominant. This is not limited to ultra-short-pulse lasers: it has been theorized that in the machining of polymer materials using ultraviolet lasers, ablation phenomena due to photochemical decomposition are dominant [6]. For the machining using the wavelengths 266 and $355 \mathrm{~nm}$, which are in the UV region, it is likely that, since the heating and evaporation were instantaneous, heat transmission to surrounding areas was minimal and the machining proceeded as ablation-like phenomena. On the other hand, at wavelengths 1064 and $532 \mathrm{~nm}$, the heating of the material was not as fast as at 266 and $355 \mathrm{~nm}$, and a certain degree of heat was transmitted to the surrounding area. As a result, heat processinglike phenomena occurred and were dominant, leading to a difference in the post-processing appearance compared with that at the UV wavelengths 266 and $355 \mathrm{~nm}$. At slow travel speeds, it is predicted that the kerf width was expanded because, heat transmission to the surrounding area increased. Note that, although we are arguing for using hole depth as an indicator of machining performance, similar results were found when calculating eliminated volume, which takes into account hole width, with $355 \mathrm{~nm}$ yielding the best machining performance of the four wavelengths used. 
The results of wavelength conversion showed that the shorter the wavelength, the smaller the maximum output power that could be obtained. For example, while the maximum output power at a wavelength of $355 \mathrm{~nm}$ was $5.0 \mathrm{~W}$, at a wavelength of $532 \mathrm{~nm}$, an output power of around $13.0 \mathrm{~W}$ can be obtained with the same device. However, even if we consider this, there is a concern that a wavelength of $532 \mathrm{~nm}$ will create greater heat effects proportional to output power level, and, therefore, a wavelength of $355 \mathrm{~nm}$ is considered to be the most suitable for wood machining. As there is also high demand for cutting in the wood industry, there has been much research on laser cutting using $\mathrm{CO}_{2}$ laser. Arai and Hayashi [7] have investigated characteristics of wood cutting in terms of their relationship to machining parameters using $\mathrm{CO}_{2}$ laser. As an example of a result, the kerf depth was about $5 \mathrm{~mm}$ when katsura (Cercidiphyllum japonicum) of density $0.47 \mathrm{~g} / \mathrm{cm}^{3}$ was cut at a travel speed of $20 \mathrm{~mm} / \mathrm{s}$ by $50 \mathrm{~W}$ of power. This cannot be compared with our results simply, it seems that the UV-laser possesses the performance equivalent to $\mathrm{CO}_{2}$ laser.

\section{Spectral reflectance}

We hypothesized that the variation in machining performance with wavelength was due to differences in the light absorptance of each of the woods. Thus, Fig. 5 shows the results of measurements of the spectral reflectance of each specimen. The three types of wood each showed roughly the same profile. Upon this, the spectral reflectance of late wood part was measured, its profile was almost same as the one of early wood in supplemental experiments. When we define the absorption of light as being inversely related to reflection (including transmission), then wavelengths with less light reflection and greater absorption produce superior machining performance, supporting our hypothesis. In

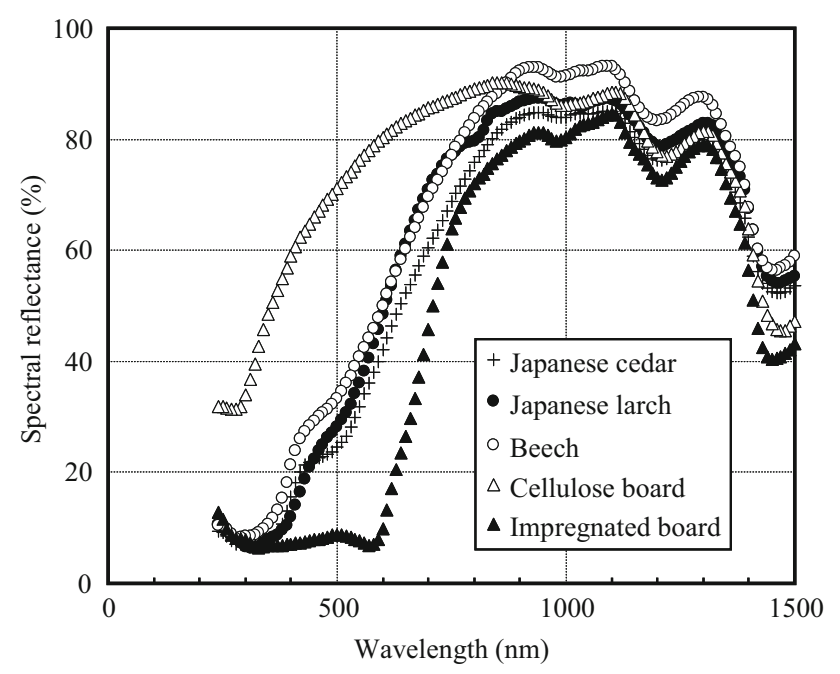

Fig. 5 Spectral reflectance other words, for wood, light reflection decreases dramatically as wavelength shortens from visible light range towards the UV range; of the laser wavelengths used, absorption was largest at a wavelength of $355 \mathrm{~nm}$.

The absorption of ultraviolet light by wood is due to lignin, which is a polymeric phenol component that makes up about $30 \%$ of wood. Yasuda et al. [8] exposed UV light to specimens of filter paper that had been impregnated with various components of wood, and used changes in color to investigate the activity of the components in response to UV light. They found that UV light's contribution to lignin was the greatest, while it contributed almost nothing to cellulose. Therefore, we hypothesized that absorption of the UVwavelength laser light occurred mainly because of the presence of lignin, which greatly improved the machining performance. Apart from lignin, the components of wood are mainly cellulose and hemicellulose. Thus, by taking measurements using a cellulose board, a material composed of cellulose without lignin, we found that the reflectance of light over the range of UV to visible light was greater than that for the woods, and its absorption was smaller. The relationship between travel speed and kerf depth for this board, after performing the same laser machining was shown in Fig. 6. For the cellulose board, even at a travel speed of $25 \mathrm{~mm} / \mathrm{s}$, kerfs could not be machined on the specimen surface to the extent that carbonization was visible; even when the speed was lowered to $5 \mathrm{~mm} / \mathrm{s}$, kerf depth was approximately $1 \mathrm{~mm}$. Next, when we tested the impregnated board, we found that, as shown in Fig. 5, spectral reflectance over the range of UV to visible light was much lower than that for the cellulose board, and reflection was particularly low between the UV range and wavelengths near $600 \mathrm{~nm}$. When the same laser machining was conducted on this board, machining

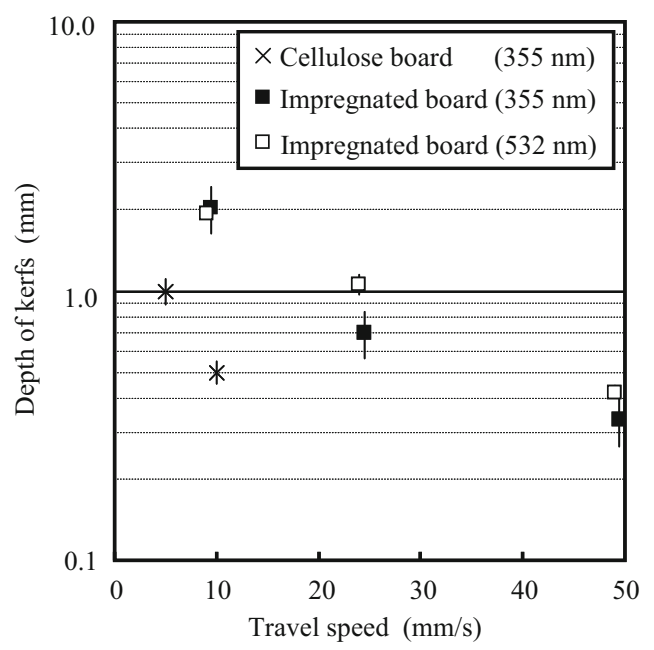

Fig. 6 Relationship between travel speed and kerf depth when machining cellulose board and cellulose board impregnated with phenolic resin 
progressed remarkably better than for the cellulose board although carbonization occurred in the area surrounding the kerfs. Furthermore, even a wavelength of $532 \mathrm{~nm}$ yielded similar results to those at $355 \mathrm{~nm}$ (Fig. 6). In short, it appears that the absorption of light drives the machining process. Note that, different from the case of wood, the heat effect was conspicuous and the kerf depth was shallow. Having high density of the board more than a series of wood is considered as the reason. This wavelength dependence has been reported in various fields in which lasers have been applied. For example, Nilaya et al. [9] applied the same wavelengths used in our study to decontamination of radioactive substances loosely deposited on stainless steel, and reported the effectiveness of using $1064 \mathrm{~nm}$. In addition, Watanabe et al. [10] reported the effects of wavelength in attempts at surface modification of PET fibers using laser irradiation, and discussed the relationship between it and light absorptance. In this study, as the structure of the polymerized phenolic resin in the impregnated board and the lignin within the wood differ completely, it is difficult to say that we confirmed the effectiveness of the lignin. However, it is highly likely that light absorptance affects machining performance.

One reason for the ablation phenomena caused by the laser can be chemical bond cleavage caused by photon energy. However, if we consider that the photon energy is smaller than the dissociation energy of the bonds of the substances in the impregnated board, it seems more likely that rapid fusion and elimination which occurred after conversion to thermal energy is the cause of the ablation phenomenon. It seems that the relationship between the heating speed at the focal point and the rate of diffusion of heat to the surrounding area is the root of the difference between the ablation-like machining, where there was little heat effect on the surrounding area, and the heat-based machining, where heat effects are seen in the surrounding area. We believe this is responsible for following observed effects: the carbonization of the machined cross section was greater for a wavelength of $532 \mathrm{~nm}$ (which had a relatively slow heating speed) than that for a wavelength of $355 \mathrm{~nm}$; the carbonization of the higher-density beech was greater than that of the cedar; and that of the impregnated board was more conspicuous. Furthermore, we believe that the kerf width at a wavelength of $1064 \mathrm{~nm}$, which exhibited greater reflection of light and an even slower heating speed, was larger because of the greater heat effects to the surrounding area.

\section{Conclusions}

Laser machining of wood has traditionally used $\mathrm{CO}_{2}$ lasers. In contrast, our previous study investigated wood machining using a type of short-wavelength laser, a UV laser, and found that microscopic hole drilling and cutting could be performed [3]. However, there exist various other types of lasers with a wavelength range shorter than that of $\mathrm{CO}_{2}$ laser. Thus, in the current study, we used lasers of wavelengths 266, 355, 532, and $1064 \mathrm{~nm}$ to perform wood cutting, and investigated wavelength dependence as well as post-processing appearance in relation to machining performance. That is, we tested for the optimal wavelength for the machining of wood. The result was that machining using the $355 \mathrm{~nm}$ wavelength laser achieved the greatest machining performance. There were also few heat effects surrounding the machined area. From an industrial perspective, although it is true that the shorter a laser's wavelength, the smaller the output power that can be obtained, if we consider not only machining performance but also the advantages that short-wavelength lasers have in terms of machining quality, then a $355 \mathrm{~nm}$ wavelength appears to be the most suitable for the machining of wood.

We hypothesized that the variation in machining performance for each wavelength was due to differences in light absorptance. When we measured the spectral reflectance of the woods, we found that wavelengths that yielded greater machining performance also produced greater absorption, supporting our hypothesis. The optimal wavelength for machining wood, $355 \mathrm{~nm}$, is UV light. Assuming that the absorption of UV light by wood is due to lignin, we prepared a lignin-free cellulose board and conducted the same kind of machining and measurements to investigate the effects of lignin. We found that the absorption of light in the UV range was low, and machining at these wavelengths was difficult. Therefore, we hypothesized that, for wood machining using a laser with a wavelength of $355 \mathrm{~nm}$, the absorption of light was mainly due to the presence of lignin, and this greatly improved the machining performance. On the other hand, when this cellulose board was impregnated with phenolic resin, there was high absorption of light between the UV range and wavelengths near $600 \mathrm{~nm}$, machining progressed well, and similar machining was achieved at a wavelength of $532 \mathrm{~nm}$ to that at a wavelength of $355 \mathrm{~nm}$. In other words, our findings support the idea that light absorptance influences machining performance.

Now that we have determined the optimal laser wavelength for wood machining at short wavelengths, we hope to work towards clarifying the machining conditions and properties for wood at this wavelength, as well as to report on its applications such as cutting, incising and its potential utilization.

Acknowledgments We extend our heartfelt thanks to the Advanced Machining Technology and Development Association for their assistance in carrying out this study. 


\section{References}

1. Listyanto T, Ando K, Yamauchi H, Hattori N (2013) Microwave and steam injection drying of $\mathrm{CO}_{2}$ laser incised Sugi lumber. J Wood Sci 59:282-289

2. Islam MN, Ando K, Yamauchi H, Kobayashi Y, Hattori N (2007) Passive impregnation of liquid in impermeable lumber incised by laser. J Wood Sci 53:436-441

3. Fukuta S, Nomura M, Ikeda T, Yoshizawa M, Yamasaki M, Sasaki Y (2016) UV laser machining of wood. Eur J Wood Prod 74(2):261-267

4. Bryan EL (1963) Machining wood with light. Forest Prod J 13(1): 14

5. Hattori N, Nakamoto Y, Kitayama S (1991) Comparison of machining performance for wood and paper between $\mathrm{CO}_{2}$ laser and YAG laser (in Japanese). The 41st Annual Meeting of Japan Wood Research Society, Matsue, Japan, p 433
6. Arai T (2013) Chap 4. Interaction of laser and substance. In: Fundamental engineering science for laser materials processing (in Japanese). Maruzen Publishing, Tokyo, p 159

7. Arai T, Hayashi D (1992) Factors affecting the laser processing of wood. I. Effects of mechanical laser parameters on machinability. Mokuzai Gakkaishi 38:350-356

8. Yasuda S, Nagaoka M, Hanzawa M (1974) Discoloration of pulps by light (in Japanese). Res Bull Coll Exp For Hokkaido Univ 31(1):1-7

9. Nilaya PJ, Raote P, Kumar A, Biswas DJ (2008) Laser-assisted decontamination. A wavelength dependent study. Appl Surf Sci 254:7377-7380

10. Watanabe H, Tanaka T, Tsuge M (1993) Surface change of poly (ethylene terephthalate) fibers by laser ablation (in Japanese). Sen'i Gakkaishi 49(4):157-162 